\section{Selling ideas at the fringe of science} Irkutsk, Siberia

Perestroika has had at least one disconcerting consequence: the emergence in the Soviet Union of fringe science as a force to reckon with. There is now, for example, a cooperative of scientists based in Leningrad whose income is sufficient to support a staff of 20 , mostly on the basis of contracts with industrial enterprises and collective farms.

One of the founders of the cooperative, Anatoly Bondarev, once a field theoretician at Leningrad, was in the Baikal district last week with his Irkutsk-based colleague Eugene Mazhous, urging the value of their techniques in insulating Lake Baikal from pollution. They offer activated water as a way of reducing pollution from industrial enterprises such as oil refineries and extrasensory cognition as a way of increasing the yield of agricultural crops.

Bondarev says that activated water, made by passing an alternating current through ordinary water, has the property of neutralizing pollutants that may be dissolved in it. As to how activated water differs from ordinary water, he says that its molecular structure retains a pattern of electric dipoles of the kind responsible both for the structure of polywater (a Leningrad invention) and the 'memory of water', coupled with the name of Benveniste.

The agricultural application of extrasensory phenomena is more shadowy, but the starting point is the argument that a farmer about to sow his seeds for the year ahead will first seek to bring himself and his seeds into harmony with the environment in which the seeds must grow. Extrasensory processes can enhance the degree of harmony, it appears. Bondarev and Mazhous say that experiments have shown that crop yields can be increased by 30 per cent even when the use of fertilizers and other chemicals is discontinued.

Publication seems to be a sore point. Bondarev says that "before perestroika, our Academy of Sciences was very sceptical of our ideas, and prevented their publication". Now, with the opening of the market in ideas, the cooperative, in the process of being separated from a larger organization called ORKON, is free to make what deals it can with industrial and agricultural enterprises. Bondarev says his cooperative has the support of the Irkutsk Executive Committee, an organ of the regional government, and that talks have been opened with the government of Bolivia about the application of the techniques in Latin America.

The cooperative also believes it will be able to exploit cold thermonuclear fusion. Bondarev says he has several ideas as to how cold-fusion processes might function, but that the cooperative will probably not follow the route chosen by Fleischmann and Pons.

\section{Nobel for oncogenes}

\section{London}

For their discovery that the oncogenes of animal tumour viruses are derived from cellular genes (proto-oncogenes), J. Michael Bishop and Harold Varmus of the University of California, San Francisco (UCSF), have won this year's Nobel Prize in Physiology or Medicine.

In the early $1970 \mathrm{~s}$, the prevailing 'oncogene hypothesis' of Robert Huebner and George Todaro postulated that the retroviral-like genes carried in the genomes of most mammalian cells were normally silent but, when activated by carcinogens, contributed to the formation of tumours. A minority view, put forward in particular by Steve Martin, Robin Weiss and Peter Fischinger, held that it was normal cell genes that were activated and were also the origin of the oncogenes of retroviruses.

The seminal experiments supporting the minority view were published in 1976 by Bishop and Varmus, with Dominic Stehelin and Peter Vogt (Nature 260, 170-173; 1976). In it, they provided evidence that DNA closely related to the $s r c$ oncogene of avian sarcoma viruses is present as part of the full complement of chicken genes, and stated that they were testing whether this DNA represented a gene that was involved in either the normal regulation of cell growth and development or in carcinogen-induced tumour formation.

A huge accumulation of data since 1976 has generalized the initial finding; almost every tumour virus oncogene is derived from a normal cellular gene. More importantly, these proto-oncogenes are active in normal cells and their products are, indeed, involved in cell signalling, growth and differentiation.

The significance of this conclusion in terms of human cancer was uncertain for some years. But since the early 1980 s it has become increasingly clear that the mutation of abnormal activation of certain cellular genes, including many of those that crop up in altered form in tumour viruses, contribute to tumour formation. The first evidence that this was so, emerged when a human tumour gene that was able to induce cancer-like properties in cultured cells turned out to be a mutated version of the oncogenes of the Rous sarcoma virus. Robert Weinberg, in whose laboratory that discovery was made, was tipped in the latest issue of The Scientist to share the Nobel prize with
Bishop and Varmus, and must, indeed, count himself as unlucky.

Both Bishop and Varmus were born and educated in the United States. Bishop, who is 53 , is an MD who took to virology at the National Institutes of Health before moving to UCSF in 1968, where he became professor of microbiology and immunology four years later. He has been director of the George F. Hooper Research Foundation at UCSF since 1981, and continues to pursue research on tumour viruses and proto-oncogenes. Varmus, who will be 50 later this year, has spent the whole of his professional life, sabbaticals apart, at UCSF. Since 1982 he has been professor of biochemistry and biophysics there, and has programmes of research on oncogenes, hepatitis virus and, most recently, human immunodeficiency virus.

Both Harold Varmus and Michael Bishop are known for their scientific
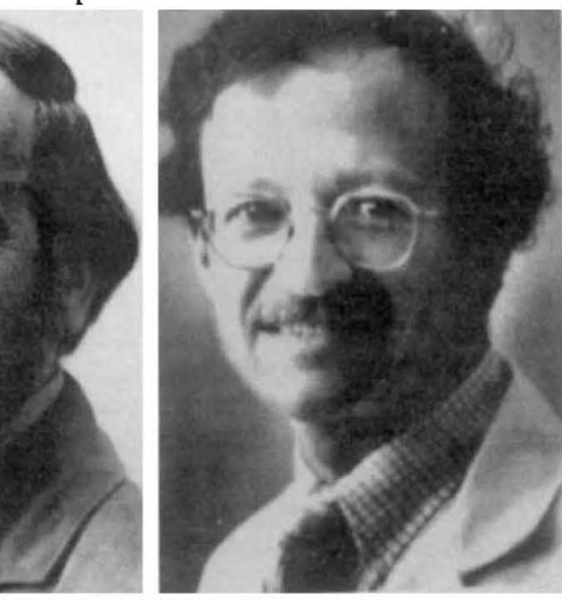
writing. The clarity of expression evident in Varmus's papers doubtless owes much to the fact that he graduated in English before turning to medicine and science. Bishop's inimitable style has oncogenes "unleashed" and "incriminated", and not "innocent bystanders or mere pawns in the tumours where they are found". Their lectures in Stockholm in December should make exceptionally good listening.

Peter Newmark

\section{FLOREY INSTITUTE}

\section{New director}

Sydney

THE new director of the Howard Florey Institute of Experimental Physiology and Medicine in Melbourne is to be John Coghlan, who is at present deputy vicechancellor for research at the University of Melbourne.

Coghlan has been deputy director of the institute since 1976 and will succeed Derek Denton, who retires on 1 January next year. Tania Ewing 